\title{
Publisher Correction: Type I interferon-driven susceptibility to Mycobacterium tuberculosis is mediated by IL-1Ra
}

Daisy X. Ji, Livia H. Yamashiro, Katherine J. Chen, Naofumi Mukaida D, Igor Kramnik, K. Heran Darwin and Russell E. Vance $\mathbb{D}$

Correction to: Nature Microbiology https://doi.org/10.1038/s41564-019-0578-3, published online 14 October 2019.

In the version of this Letter originally published, in the key in Fig. $4 \mathrm{~b}$ the red squares were mistakenly labelled B6.Sst $1^{S} \mathrm{IlIrn}^{-/-}$; they should have been labelled B6.SstI ${ }^{S} I l 1 \mathrm{rn}^{+/+}$. This has now been corrected.

Published online: 16 April 2020

https://doi.org/10.1038/s41564-020-0718-9

๑ The Author(s), under exclusive licence to Springer Nature Limited 2020 